\title{
Challenges and opportunities for fleet- and métier-based approaches for fisheries management under the European Common Fishery Policy
}

Ulrich, Clara; Wilson, Douglas C.K.; Nielsen, J. Rasmus; Bastardie, Francois; Reeves, Stuart A.; Andersen, Bo Sølgaard; Eigaard, Ole Ritzau

Published in:

Ocean \& Coastal Management

Link to article, DOI:

10.1016/j.ocecoaman.2012.06.002

Publication date:

2012

Link back to DTU Orbit

Citation (APA):

Ulrich, C., Wilson, D. C. K., Nielsen, J. R., Bastardie, F., Reeves, S. A., Andersen, B. S., \& Eigaard, O. R. (2012). Challenges and opportunities for fleet- and métier-based approaches for fisheries management under the European Common Fishery Policy. Ocean \& Coastal Management, 70, 38-47.

https://doi.org/10.1016/j.ocecoaman.2012.06.002

\section{General rights}

Copyright and moral rights for the publications made accessible in the public portal are retained by the authors and/or other copyright owners and it is a condition of accessing publications that users recognise and abide by the legal requirements associated with these rights.

- Users may download and print one copy of any publication from the public portal for the purpose of private study or research.

- You may not further distribute the material or use it for any profit-making activity or commercial gain

- You may freely distribute the URL identifying the publication in the public portal 
Ocean \& Coastal Management Volume 70, December 2012, Pages 38-47

http://dx.doi.org/10.1016/j.ocecoaman.2012.06.002, (c) 2013 Elsevier

DTU Aqua

National Institute of Aquatic Resources

\title{
Challenges and opportunities for fleet- and métier-based approaches for fisheries management under the European Common Fishery Policy
}

$\underline{\text { Clara Ulrich }}^{\mathrm{a}}$, Douglas C.K. Wilson ${ }^{\mathrm{b}}$, J. Rasmus Nielsen ${ }^{\mathrm{a}}$, Francois Bastardie $^{\mathrm{a}}$, $\underline{\text { Stuart A. }}$

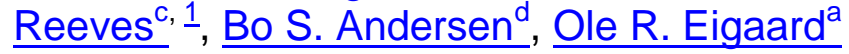

${ }^{a}$ DTU Aqua, Charlottenlund Castle, DK-2920 Charlottenlund, Denmark

b IFM AAU, Department of Development and Planning, Fibigerstræde 13, 9220 Aalborg $\varnothing$, Denmark

${ }^{c}$ Cefas Lowestoft Laboratory, Pakefield Road, Lowestoft, NR33 OHT, UK

${ }^{d}$ DTU Aqua North Sea Science Park, DK-9850 Hirtshals, Denmark

\begin{abstract}
The inconsistency of single-species objectives in a mixed-fisheries context has repeatedly been highlighted as a key issue in the current European Common Fishery Policy, and it has long been suggested that this issue would be better addressed through fleet (group of vessels) and métier (type of activity) - based approaches. Since the late 1980s, when such approaches were first introduced, there have been substantial developments in this area of science, to the point where the concepts of fleet and métier now underpin the whole EC Data Collection Framework. However, their implementation in the management system has been slow and difficult, being hampered by a number of intrinsic issues. Mixed fisheries are an ongoing "governance headache" combining management complexity, scientific uncertainty and political sensitivity.
\end{abstract}

This paper summarises the current state of play for fleet-based approaches in EU fisheries management, and highlights our views on both their potential and the challenges they face in the context of the future CFP. As a convenient layer between the current single-stock level and the level of the individual vessel, fleet/metier- approaches could potentially address a wide range of issues, especially with regards to the policy emphasis on ecosystem-based fisheries management. However, the rigid categorisation they induce may not properly address the flexibility of individual vessels, and should therefore be supplemented by more detailed considerations at the local scale.

Keywords: Common Fishery Policy (CFP), Data Collection Framework (DCF), métier, fleet dynamics, Ecosystem-Based Fisheries Management (EBFM), mixed-fisheries, results-based management

*Corresponding author: clur@aqua.dtu.dk

Article first published online: Dec 2012

Please note that this is an author-produced PostPrint of the final peer-review corrected article accepted for publication. The definitive publisher-authenticated version can be accesses here: http://dx.doi.org/10.1016/i.ocecoaman.2012.06.002, (c) 2013 Elsevier 


\section{Introduction}

\subsection{The problem}

There is a general understanding that mixed-fisheries aspects are a key issue in the traditional singlestock management approach, because of the evidence that catches of the various species are interlinked due to technical interactions between different fleets and gears (Figure 1). In addition, availability, abundance and economic attractiveness differ across species, adding to the complexity of the problem. This issue is well illustrated by the demersal fisheries in the North Sea over the 2000s. The North Sea cod stock had declined to a very low biomass while the stock of haddock, which to a large extent is caught together with cod, had reached very high biomass levels (ICES, 2011b). Effort reductions have been introduced through the successive European cod management plans (EC, 2004 and EC, 2008b), but the central management measure for these stocks has remained single-stock Total Allowable Catches (TACs), which in practice have regulated landings rather than catches. One result is that vessels may exhaust the cod TAC before the haddock TAC, and the subsequent cod catch may then have to be discarded. Hence the cod TAC, despite being based on advice consistently intended to reduce fishing mortality, has not achieved its intended conservation benefit (STECF, 2011a). Bannister (2004) identified the mixed-species nature of the fishery, along with its international dimension, as the two main factors contributing to the cod decline.

In theory, fleet-based approaches are valuable improvements to the current approach of managing single-species fish stocks (Vinther et al., 2004; Nielsen and Limborg, 2009). The long history of the EU Common Fisheries Policy (CFP) of aiming at, but often failing to, manage complex fisheries through TACs provides an illustration of the limits of the current stock-based management approach. When implemented in their most usual form in EU, i.e. involving competitive shared quotas and landings control, single-stock TACs are not able to control total removals and fishing mortality in mixed-fisheries (ICES, 2011b, STECF, 2011a). 
In practice however, the implementation of fleet-based approaches in the management system has been slow. Since the seminal work of Laurec et al. (1991), the topic has attracted considerable scientific attention. Twenty years of European research in fleet and fishery analyses have led to substantial improvements in the data collection, understanding of processes and improved standardization across nations. In spite of this, the scientific advice provided by the International Council for the Exploration of the Sea (ICES) has only recently made some progress in accounting for technical interactions in a quantitative way (ICES, 2011a; Ulrich et al., 2011). Some of this inertia undoubtedly reflects the complexity of the fisheries involved. ICES (2011a) compiled data for all countries, fleets and gears catching demersal target species in the North Sea. Even after aggregation of the minor fleets and gears, the data still include 72 different fleet, gear and métier groupings. However, the problem is clearly not only a scientific one. In 2011, the paradigm that decreasing single-stocks TACs is the path towards sustainability is still prevalent in the political action of the European Commission (EC, 2011a). The maintaining of the principle of relative stability, ensuring fixed shares of the individual TACs to the various Member States, has inhibited the political ability to apprehend mixed-fisheries in a sensible and integrated approach. With such a combination of high uncertainty, high political sensitivity, and associated complex science, Wilson and Jacobsen (2009) call mixed-fisheries management a "governance headache".

This paper aims thus both at describing the current state of play regarding the actual implementation of of fleet- and fishery based approaches in EU, focusing on some intrinsic issues that have been of hindrance, and at discussing the opportunities and challenges for these approaches under the future CFP. Our case is based on our experience (mainly from North Sea and Baltic Sea regions), both as providers of scientific advice for fisheries managers and as collaborators on a suite of research projects studying fleet dynamics and fisheries management. It should therefore only be taken to represent a subset of the wide range of knowledge and opinions to be found around this broad topic. 


\subsection{Glossary}

First of all, the basic concepts must be defined. The terminology has evolved over the years. ICES (2003) initially considered three types of fishing units: the fleet, the fishery, and the métier. In 2008, the European Data Collection Framework (DCF; EC, 2008a) retained only two concepts, which we adopt for this paper: A fleet (or fleet segment) is a group of vessels with the same length class and predominant fishing gear during the year. Vessels may have different fishing activities during the reference period, but might be classified in only one fleet segment. A métier is a group of fishing operations targeting a similar (assemblage of) species, using similar gear, during the same period of the year and/or within the same area and which are characterized by a similar exploitation pattern. As such, the fleet describes the vessels while the métier(s) describes the fishing activity(ies) in which the fleet engages (Figure 1).

\section{State of the art: Current implementations at the European}

\section{Union level}

\subsection{Fleets and métiers in the CFP}

The European Commission (EC) has long expressed its interest in fleet-based approaches. In 2001 the Green Paper (CEC, 2001) underlined that "TACs can only play a limited role in the management of fisheries in which many species of fish are taken simultaneously by each operation of the fishing gear (the mixed or multi-species fisheries) (...). Mixed fisheries are prevalent in Community waters and therefore it may be preferable to manage groups of stocks for well-defined fisheries. The setting-up of a true effort management regime could be one of the means to approach multi-species management."

A more recent Green Paper (CEC, 2009), recognized again fleet-based approaches as a one key area of interest for the future. Ultimately, the proposal on the reform of the European Union's CFP (EC, 2011b) provides a concrete context for this. Long-term management plans have been an important 
component of EU fisheries management since 2002. Public consultation in relation to the recent reform proposal has found very strong support for the implementation of long-term management plans. The current proposal widens the basis for the use of management plans as follows:

"Multi-annual plans should where possible cover multiple stocks where those stocks are jointly exploited. The multiannual plans should establish the basis for fixing fishing opportunities and quantifiable targets for the sustainable exploitation of stocks and marine ecosystems concerned, defining clear timeframes and safeguard mechanisms for unforeseen developments."

These ideological seeds, thus planted long ago, have so far yielded two major realizations. We describe them below.

\subsection{The Data Collection Framework}

Many years of development in data collection programs have led to a standardized European sampling program for fisheries biological and economic data based on fishing activities as sampling strata (EC, 2008a). It specifies the standard for national sampling programs, using the fleet as the basis for economic data sampling, and the métier as the basis for biological data sampling. Integrating fishing activities represents a major change compared to the EU Data Collection Regulation (DCR) previously in force (EC, 2001).

The DCF defines métiers according to a hierarchical structure using six nested levels: Level 1Activity (fishing/non fishing), Level 2- Gear class (e.g. trawls, dredges), Level 3- Gear group (e.g. bottom trawls, pelagic trawls), Level 4- Gear type (e.g. Bottom otter trawl, Bottom pair trawl), Level 5- Target assemblage based on main species type (e.g. Demersal fish vs. Crustaceans or Cephalopods), Level 6- Mesh size and other selective devices. In addition, economic variables should be reported for fleet segments defined by the dominant gear (in terms of fishing effort) used by vessels, and for six length classes. 
The definitions of the DCF métiers were initiated during two pan-European workshops (EC, 2005a, 2006), and are still extensively debated (ICES, 2010). No unified quantitative method has yet been agreed (see section 3 below), leaving some room for interpretation at the national level. This has slowed the development of a standard, generic EU approach, leading to continuing national differences in métier definitions within the same EU region.

In summary, the DCF has from 2009 led to major steps towards quantification and monitoring of fleets and métiers, through improved agreement on the basic concepts and definitions, as well as increasing facilities and collaboration to exchange data. However, it is also true that substantial national differences still exist, and further initiatives are still necessary in order to achieve full consistency across member states (STECF, 2011b, Deporte et al., 2012).

\subsection{Métier-based effort management}

In parallel to the work undertaken within DCF, but without any linkages to it, métier-based effort regulations have been enforced in European waters. Effort restrictions (days at sea) were first introduced in 2003 to supplement TACs in areas covered by the cod recovery plan (EC, 2004), and have been updated annually since then. Subsequently, similar effort restrictions were introduced in relation to southern hake and Nephrops, western channel sole and sandeel fisheries. Categories (métiers) for days at sea limits were defined in terms of gear type and cod-end mesh size combinations. 'Special condition' categories were also defined such that a vessel qualifying for such status would be entitled to a greater number of days at sea than the default value for the same gearmesh size group.

These categories are therefore quite different from the DCF métiers described above, and only limited consideration has been given to this. Reeves et al. (2008) provided a useful overview on the processes and scientific issues underlying these days at sea regulations. While the establishment of the DCF involved an extensive and long scientific process based on available information, in contrast, the days at sea regulations were designed and implemented over a very short period of time and without any 
clear scientific basis. Subsequently, sub-groups of the European Commission's Scientific, Technical and Economic Committee for Fisheries (STECF) were tasked to evaluate the effects of these regulations. This requires extensive compilation of effort and catch data, aggregated such that the hierarchy of gear, mesh size and special condition status match those in the annual Council Regulations fixing EU fishing opportunities and associated conditions in EU Community waters (see for example STECF 2010a). These exercises proved to be difficult, time-consuming, error-prone and inconsistent across EU Member States. A main reason is that the scientific data are collected following DCF standards, while monitoring the days at sea management requires more detailed information of gear descriptors, which are not usually available in the data provided to national scientific institutes..

Furthermore, the implementation of the days at sea system led to strong protests from the fishing industry questioning both its fairness and its basis. The system was implemented as a top-down command and control system, and was conceived on the assumption that cod catches could simply be reduced by reducing the cod-directed fishery. As cod is caught by most gears in the North Sea, most demersal fisheries were affected by the system and the industry considered this conservation measure to be neither efficient nor fairly shared. The protests pressured the Member States to exempt some of their fleets. This resulted in increasingly detailed micromanagement, and an even more complex set of regulations that basically changed every year (Table 1). In 2008, the system was no longer considered sustainable, controllable and effective by the EC, and a complete new approach for effort control was agreed with Members States. This moved from limitations at the level of the individual vessel and métier to limitations at the level of the Member States over broader gear/mesh size categories, thus allowing for more flexibility. This system was implemented in 2009 (EC, 2008b), based on a reduced number of categories, but with new mechanisms aiming at encouraging cod-avoidance behavior in the fishing industry. STECF (2011a) conducted a detailed evaluation of that plan. The increased use of incentives-based management was evaluated as a positive innovation, but it was also pointed out that there was still little support from the industry towards the effort constraints induced by the plan. Interestingly, the so-called incentives in the cod plan are in reality almost all negative in the sense that 
action to avoid cod will result in reductions in income (sub-optimal areas; loss of fish through changes in selectivity), as will no action (reduction in fishing effort opportunities). Each business needs to weight up the degree of loss associated with these negative choices, leading to a somehow unclear perception of the incentivizing mechanisms and a difficult monitoring of their effects (Holmes et al., 2011, Needle and Catarino, 2011).

\section{A fundamental challenge: agreeing on basic definitions and}

\section{categorization.}

The two initiatives described in section 2 are the most advanced attempts to implement operational fleet- and métier-based approaches so far. They clearly illustrate the difficulties faced in practice and . there is also a striking difference in the definition of métiers that have been used in these two cases. The two processes have been conducted independently, illustrating the risks of mismatch occurring if science is setting its agenda without a solid anchor to management rules, or if management regulations are implemented without insuring that scientific support will have the ability to monitor and evaluate their outcomes. This difference leads us to reflect on a fundamental issue in fleet- and métier-based approaches, which relates to the basic difficulty of categorizing fishing activities.

Obviously, implementation of any fleet based approach requires the definition of management units (fleets and/or métiers), as well as of quantifiable rules to populate fishing trips into métiers and fishing vessels into fleets. The concepts of fleets and métiers are appealing as they offer a convenient and valuable trade-off between reducing the complexity of the system into few tractable categories, while maintaining sufficient information on its characteristics and dynamics. However, defining these concepts has in itself been a primary hindrance to their operational implementation so far. It is not simply, as we often hear, that things are not "clearly defined", it is more than that. Many of the concepts we have to deal with in mixed fisheries are 'essentially contested concepts' (Gallie 1955), meaning that their definition always depends on the speaker's interest in how it is defined (Wilson and Jacobsen, 2009). 
Fleets and métiers are only aggregations of individual operations and vessels operated by humans, and as such are not natural entities but social entities created and continually redefined by human beings. Because each vessel (and each trip, respectively) is unique in terms of catch rate, fishing type, profitability, incentives, etc., it is very difficult to get simple and meaningful averages and to identify key fishing patterns.

Métiers were created by scientists and managers as analytic and bureaucratic units, being relevant to management measures in terms of e.g. vessel size and gear. These kinds of definitions are necessary for both promulgating and analyzing the impacts of management measures, but may not reflect the true dynamics and reality of fishing (Wilson and Jacobsen, 2009). We illustrate here the differences, and even antagonisms, that arise in different approaches to the problem of categorization.

\subsection{Scientific approach}

As explained above, the DCF requires the categorization of fishing activities based on hierarchical criteria, but this can be achieved in any number of ways. ICES (2003) provided general concepts and ideas, but no clear quantitative guidelines. Indeed, a variety of approaches have been used in a number of case studies over the last two decades: see reviews in Marchal (2008), Reeves et al. (2008) and Deporte et al. (2012), and references herein. Recalling that métiers should reflect the fishing intention but that this often cannot be observed directly, Marchal (2008) described the classification approaches as being either input-based, output-based, or combined methods. Input-based methods either make use of existing records of the technical features of fishing trips, e.g. gear and mesh size used, fishing grounds visited, season, fishing power; or build on direct interviews with stakeholders. Output-based methods assume that catch profiles perfectly reflect fishing intention, and build therefore on empirical or statistical analyses of landings or catches in weight or in value. Combined methods relate catch profiles (outputs) to fishing trip characteristics (inputs). Marchal (2008) compared some of these approaches analytically, and concluded that they could result in contrasting outcomes for a number of fleets. Species assemblages cannot be easily defined from logbooks, since (1) as primary issue, 
discards are usually not included in these analyses due to low sampling levels, and therefore the data available provide an imperfect estimate of the actual catch compositions. This can furthermore be biased by factors such as quota availability, market prices, traditions, etc, (2) species assemblage is an

221

222

223 outcome of the fishing action, but may not accurately reflect the true targeting intention of the fishers due to imperfect knowledge of the underlying resource distribution, being therefore significantly influenced by skipper skills (Mahévas et al., 2011) and (3) clustering of fishing operations based on species assemblage is not very robust when a continuum is observed between different types of target species (e.g. "mixed categories" in between clear "Nephrops" operations and clear "demersal fish" operations). Clusters are also not necessarily constant over time if species abundance varies.

Similar methods and issues apply to the grouping of fishing vessels into fleet segments. Vessels can be aggregated on the basis of their main activity following identical statistical approaches (e.g. Pelletier and Ferraris 2000, Ulrich and Andersen, 2004), on the basis of their technical characteristics (e.g. main gear and vessel size, ICES, 2011b) or according to their fishing efficiency (Marchal et al., 2001). In these cases, further work may be necessary to distinguish between the vessels belonging to one management unit and area from one belonging to another, for example using revenues thresholds or home port.

In conclusion, no unified methods have yet been agreed upon for the standard scientific definition of fleets and métiers, despite a significant activity in this field. There is no easy solution to these issues and problems, which are intrinsic to the categorization process. The only way forward is to increase the regional and European collaboration in order to establish European standards which would be agreed as supranational compromises (Deporte et al., 2012). Defining regional métiers would also reduce the needs for costly sampling at the national métier level, both by potentially reducing the number of categories to the broader common and significant patterns (Deporte et al., 2012), and by promoting exchanges of biological samples across nations within unified categories. 


\subsection{Fishers' approach}

243 Some stakeholders are questioning these approaches to fleets and métiers. Stakeholders recognise the need for such definitions to address a number of complex issues in fisheries management, but their perception may differ widely from the above views. Indeed, the categorization issue has been relevant to them only recently, since they did not have to deal with it under the usual single-stock TAC system, where they would individually "race for fish" under national competitive quotas or operate under individual transferrable quotas (ITQs). Under such a system, fishers could with relative ease switch from one fishery to another based on seasonal fluctuations of species abundances and prices. The introduction of rigid and somewhat arbitrary fisheries-based regulations (such as the days at sea limitations), represented a major violation of their free choice and a significant restriction to their traditional fishing patterns (STECF, 2011a), and this made them consider the fairness of the category definitions. Jacobsen et al. (2009) and Wilson and Jacobsen (2009) performed an extended analysis of stakeholder views on the issue of fleet and métier definition and concluded that fishers have a strong wish to preserve their seasonal flexibility, arguing that gear says very little about what kind of fish will be caught, particularly for the coastal multi-purposes vessels. They are therefore reluctant to management based on narrow categories and would prefer broader and less constraining grouping allowing for individual variability. However the focus of management on the individual stocks, with individual quotas and licenses, may force the vessels towards a growing polarization and specialization in one type of fishing instead of shifting according to e.g. season and/or area (Pascoe et al., 2010) This, in turn, may lead to the somehow paradoxical situation mentioned above, where, in order to cope with pressure from their own industry, Member States have pushed the initial broad cod plan categories defined in 2003 towards detailed micro-management and multiple categorization.

In terms of fisheries, one interesting example was a reflection by a stakeholder within the North Sea Regional Advisory Council (RAC), quoted by Wilson and Jacobsen (2009). The stakeholder noted that the fisheries referred to bear no resemblance to the kinds of fisheries and métiers explained above, being based on the main (group of) target species in the demersal North Sea fishery but without 
reference to the mesh size. Wilson and Jacobsen (2009) also found that the issue of defining target species and by-catch may be just as problematic to fishers. It is of no direct concern for stock assessment whether mortality results from catching a targeted or non-targeted fish (unless this results in unrecorded discard or inaccurate commercial CPUE indices). Therefore these concepts have not been systematically investigated by fisheries scientists. NGOs are often more concerned by target and by-catch issues. A clearer distinction between the two categories would make it easier to claim for more selective fishing practices limiting unwanted by-catch. Fishers on the other hand aim at gaining profit from the species assemblage that they harvest, and do not support assigning certain fish to bycatch categories that may be more subject to restrictions, unless there is a strong reason to do so (Wilson and Jacobsen, 2009).

In summary, harmonizing the categorization of the basic units (fleets, métiers and target species) is a fundamental prerequisite for any future implementation in management. The groups defined should ultimately be quantifiable (i.e. should link to the data available for monitoring), manageable and supported by stakeholders.

\section{Additional issues and challenges in fleets/métiers-based}

\section{approaches}

In addition to the above, a number of issues remain in the implementation of fleet-based approaches,mostly linked to the quantification of effort. These are not new topics, so we will not develop these here, but refer instead to comprehensive reviews such as those by Motos and Wilson (2006) and Reeves et al. (2008). In short, important issues are i) there is a continuous change in the fishing power of the fleets, among other as a result of technological improvements and increased fishers knowledge (Branch et al., 2006; Eigaard, 2009; Eigaard and Munch-Petersen, 2010). ii) The detailed dynamic of effort and catches is insufficiently monitored, with logbook declarations at the scale of the fishing day and geographical square (Branch et al. 2006; Andersen et al. 2012; STECF, 2010a). iii) The relationships between fishing effort, fishing mortality and catches are still poorly 
understood (e.g. Marchal et al., 2001, 2006, 2007; van Oostenbrugge et al., 2008; STECF, 2011a),. iv)

There is still limited knowledge about the basic drivers of the fleet's dynamics, which may jeopardize the anticipated effects of management (Andersen et al., 2010, 2012; Fulton et al., 2011); and v) The effective fishing effort being a combination of input factors, the regulation of one type of input (e.g. fishing days or vessel size) may be compensated by increasing other unregulated inputs (input substitution, Pascoe and Robinson, 1998).

These issues make it very difficult to measure, compare and scale the efficiency of metiers and fleets between each other and between countries. Interestingly, most of these issues represent mainly a hindrance to prescriptive input control. This underlines that, against a common belief (cf. e.g. CEC, 2001), mixed-fisheries may actually not necessarily be better addressed by effort control rather than catch control. One concrete example of this is shown by the Faroe Islands, which have moved from TAC management to effort-based management. In spite of a relatively favourable environment comprising a small scale and local fishery, limited extent of mixed-fisheries interactions and sustained stock productivity, the system has overall proven to be little flexible and not fully successful in reducing fishing mortality (Nielsen et al., 2006; Jákupsstovu et al., 2007, Baudron et al., 2010, Eigaard et al., 2011).

\section{Opportunities for fleet-based approaches in the future}

\section{Common Fisheries Policy.}

The previous chapters have underlined the challenges linked to any implementation of fleet-based approaches to management. However, these nevertheless bear great potential for improvements compared to the current system.

\subsection{New technologies for monitoring and modelling}

As a counterpart to the many arguments above that would argue against the operational use of effort control in fleet-based approaches, it is worth emphasising that rapid technological developments are 
providing new monitoring tools, which increasingly address some of these shortcomings, and improve the feasibility of the approach. For example (with regards to point ii) above), access to individual Vessel Monitoring System (VMS) data allows the derivation of more precise estimates of the spatial distribution of effort and landings (Bastardie et al., 2010b; Hintzen et al., 2012), and more in-depth investigation of the links between both. These tools can also supplement other particular concerns when assessing e.g. the impact of fleet-specific activities on the sea floor and benthic communities (Fitzpatrick et al., 2011), and provide information to the broader marine spatial planning and EU Marine Strategy Framework Directive (MSFD, see also section 5.3 below). Improved monitoring is also reinforced by the introduction of electronic logbooks, or by mounting video cameras on fishing vessels to report for fully documented fishery (Kindt-Larsen et al., 2011). Thanks to these tools, continuous improvements on the quantification (nominal vs. effective) and the qualification (e.g., low vs. high impact for a given pressure indicator) of the fishing effort are expected to be gained in a near future. these should give further insights to support the development of fleet-based management.

The requirements for assessing potential uncertainties, misuses (e.g. non-compliance), pitfalls or side effects of management options to properly meet the overall objectives of sustainability also call for appropriate modelling tools (with regards to points i) and iii) in section 4 above). A variety of modelling frameworks have been developed in recent European research projects, and some are particularly generic and flexible for addressing a wide range of issues (e.g., the FLR library in R, Kell et al., 2007). Their continuous development provide improved options for coupling and integrating the complex dynamics of multiple stocks, fleets and management layers (Figure 2), allowing the evaluation of various management scenarios at different scales (cf. recent works by e.g. Pelletier et al., 2009, Andersen et al., 2010, Bastardie et al. 2010c, Ulrich et al. 2011, and reviews in Reeves et al., 2008, Prellezo et al., 2012).

One step further into effort modelling is maybe done by directly simulating the economic activity of individual vessels in an Individual-Based Model (e.g. Millischer and Gascuel, 2006, Beecham and Engelhard 2007, Bastardie et al. 2010a, Poos et al., 2010), which can advantageously capture the 
differences in characteristics, incentives and dynamics existing across individual vessels and thus improve the bio-economic realism of the modelling (addressing the points iv) and v) above). Pros and cons of fleet-based modelling vs. individual-vessel-based modelling will certainly shape future developments in the implementation and monitoring of fishery management and spatial marine planning.

In conclusion, the landscape of fisheries and fleet-based science and technology is evolving rapidly, opening for new usages and potentials. We have considered a number of these, which could contribute directly to the objectives of the future CFP and MSFD.

\subsection{Mixed-fisheries management plans}

An increasing number of European stocks are being managed through long-term management plans (LTMP). In many cases these plans are based on F-indicators resulting from single-stock assessments. As such, they are mostly an extension of the current stock-based system incorporating more long-term considerations. Single-stock TAC-based management is not challenged, it is simply made less dependent on scientific uncertainty through limitations in its inter-annual variability. However, the complex processes involved in the actual harvesting are often disregarded or loosely summarized into “implementation uncertainty” (Rosenberg and Restrepo, 1994) when evaluating the effectiveness of these management plans, even though, fleets dynamics might potentially affect this effectiveness in ways that cannot be necessarily anticipated (e.g. Bastardie et al. 2010c, Andersen et al., 2010). There are currently only few cases where technical interactions have been explicitly integrated in EU fisheries management. One is the case of the North Sea flatfish (sole and plaice) management plan (EC, 2007), whose setup built on a long previous history of modeling of mixed-fishery interactions in the Dutch beam trawl fishery (e.g., Kraak et al., 2008 and reference therein). Noticeably, this fishery presents a relatively simple configuration with only two species and relatively few and homogeneous fleets involved, implying that the pre-required categorization of fishing activity described above was easier to solve. Another exception is the management plan of Nephrops in the Iberian Peninsula (EC, 
2005b), the harvest control rule of which explicitly accounts for the fishing mortality of Southern hake, which is caught in the same mixed fishery.

Clearly, fleet-based approaches have a real potential for designing integrated mixed-fisheries management plans at the regional level, even in complex fisheries. Furthermore, accounting for fleets and métiers is central to integrated bio-economic management and advice. It allows for more direct and effective bio-economic and socio-economic evaluation of consequences of management. The recent history of demersal fisheries in the North Sea again provides a useful case study. In spite of the well known and relatively well studied mixed-fisheries interactions, separate single-species management plans have been adopted for cod, haddock, saithe and whiting. A Nephrops management plan is also under development. The linkages between stocks have so far not been integrated in the design of these plans, and only the ex-post evaluations conducted afterwards shed light on the risks of implementation error linked to their potential inconsistencies (Hamon et al., 2007, Ulrich et al., 2011, STECF, 2011a).

To summarise, we believe that in spite of the implementation hurdles explained above, acknowledging these mixed-fisheries issues and integrating these from the beginning in the design of the management plans would be less risky than ignoring these. As mentioned in the introduction, integrated regional approaches have long been acknowledged by the EC, but it is only now, in the frame of the current reform of the CFP, that the consideration of fleet-based management plans is starting to take its entire political dimension, and new developments in their design will emerge in the very near future. Indeed, a STECF Expert Group is scheduled in 2012 to formulate suggestions for bringing the North Sea cod management plan in its wider mixed-fisheries context (see also section 5.4 below), and this work might yield useful learning.

\subsection{Ecosystem-Based to Fisheries Management}

Management of fisheries and marine resources is moving towards Ecosystem-Based Fisheries and Marine Management (EBFM / EBMM) as anticipated by the EU MSFD. Spatial planning in particular 
is coming increasingly into focus, and both ecosystem aspects and all types of anthropogenic impacts on the marine environment have to be considered, within an integrated fisheries management approach. Advice on impacts on non-target commercial species, but also on those other components of the ecosystem that are impacted by fishing activities, is needed. In this respect, the incorporation of fleet and fishery information provides a bridge between the traditional single species advice and the ecosystem approach to fisheries management, by recognizing that fisheries can have a wider and diverse range of impacts than just on the major target species (Nielsen et al., 2006; Tserpes et al., 2006; Ulrich et al., 2008, Gascuel et al., 2012). The explicit representation of métiers and fleets also means that these can be more easily mapped and distinguished in the areas to be managed (e.g. Hintzen et al., 2012), than is the case with the stock-based approach alone.

Importantly, there is an inherent difficulty in applying fleet- and métier-based approaches at a highly disaggregated spatial scale. Complex interactions between stocks, fleets, management measures, and the environment are common components of mixed fisheries at the local scale. Several types of regulations may act on top of each other, making it difficult to evaluate the impacts of the individual regulations on fishers' access to their livelihood. Therefore, attempts to locally manage mixed fisheries based on complex definitions of fleets, may reduce fishers' operational flexibly, which can, in turn, interfere with the implementation of EBFM. An example of this was given by the "Invest in Fish" initiative, ( Squires and Renn, 2011) which aimed to gather information on all usages of marine living resources in the South West of England through detailed description of commercial and recreational activities and stakeholder's negotiations. While this project led to a positive experience of good communication and governance, no consensus emerged about management actions to be taken because of the high complexity and uncertainty.

This local complexity makes us believe that, while considering fleets- and métiers for EBFM is fully relevant for defining objectives at a regional scale and monitoring trends in fisheries development, the actual management implementation to achieve these objectives would potentially be more successfully 
achieved by leaving it up to the individual actors to reach given results within this frame rather than prescribing fixed rules to fixed groups. This idea is developed in the next section.

\subsection{Results-based management}

421 The European Commission has acknowledged that the current centralised and "one size fits all"

422 single-stock management might not account properly for the diversity of regional situations, particularly with regards to mixed-fisheries interactions.. Hence, the development of regional approaches to management might be encouraged in the future CFP (EC, 2011b).

One direction that is already promoted within the current CFP is the "results-based management" (RBM) or "outcome-oriented management" (Holland, 2007) linked to a "reversal of the burden of proof" so that the industry is responsible for demonstrating that it is in compliance with the limits that have been set on its ecological impacts (Fitzpatrick et al., 2011). A results-based management approach envisions two complementary processes. One of these is the setting of management objectives and corresponding limits on the environmental impacts that will be allowed for user groups. In an ecosystem-based approach this process would mean developing operational constraints based on limits set at government level. The second process is the development of exploitation plans that allow the user groups to undertake economic activities while remaining within these limits. The latter of the two processes is carried out by the user groups, in cooperation with scientists, and centred on meeting the reversed burden of proof, i.e., how the industry will be monitored and held accountable for staying within the set limits would have to be part of their plan.

One highly relevant benefit of RBM for mixed-fisheries management is the removing of the need for precise and detailed fisheries definitions for prescriptive management; as they would be defined by users themselves. Management measures proposed within the context of RBM are applied at the level 440 of local fishery or fleet segment, rather than at the level of the stock. Fleets and métiers will still have 441 to be defined in a political sense to define the groups entering into these contracts. Therefore, this model suggests a strategy for handling the multi-scale, multi-stakeholder problem of processing 
information and making decisions for mixed-fisheries management. It would also allow the industry

444 flexibility in shifting to changes in markets, fish abundance and avoiding ecological impacts (Wilson and Jacobsen 2009). Reliance on a single type of management measure with an extensive impact such as a TAC may therefore be supplemented or supplanted by local measures operating within the frame of this global approach.

RBM approaches have been used successfully in various places around the world. An example with relatively small scale fishing enterprises is Nova Scotia's RBM approach for mixed groundfish fisheries. Fishing Conservation Harvest Plans are adopted by groups of fishers as a formal contractual agreement with the Canadian Authorities. These contracts meet the sustainability requirements while shifting much of the management responsibility to county-based Management Boards (Loucks 1998,. Ulrich and Wilson 2009). The Management Boards are all operated differently, which is part of the idea of local control (Charles et al. 2005). A much larger scale example is found in the pollock fishery in the Gulf of Alaska. Here the industry is organized into cooperatives that fulfil three functions: 1) The allocation and transfer of both pollock harvest shares and limitations on species other than pollock including prohibited species catch; 2) bycatch reduction; and 3) monitoring and enforcement (Witherell et al. 2000). Wolff and Hauge (2009) found that this system has worked very well, especially in regard to fisheries conservation. The Marine Stewardship Council (MSC) eco-labelling scheme is increasingly one of the best examples of a basic RBM approach in fisheries. MSC has created a broad set of criteria for sustainable fishing based on three principles: sustainable fish stocks, minimising environmental impact and effective management. The first two principles set the groundwork for the limits that MSC imposes on a fishery if it is to carry an MSC label, and the third sets the burden on the fishery to prove it is meeting the standards. The MSC uses scientist certifiers to work in detail with fishing fleets to decide how indicators to express these principles can be fairly established, measured and met in their particular situation.

In Europe, the current EC Cod Plan (EC, 2008b) provides again a useful illustration of attempts at implementing RBM in complex mixed-fisheries. There, the metiers are defined at the level of Member 
State and broad range of activity, but internal flexibility is left to individuals to comply with the allocated effort threshold. Significant changes in dynamics of entire fleet segments have been initiated (Kindt-Larsen et al., 2011; Needle and Catarino, 2011, STECF, 2011a), underlying the importance of setting the incentives right at the level of the vessel or group of vessels (Hilborn, 2007).

Implementing RBM in Europe will not be easy, both with regards to implementation and enforcement (Fitzpatrick et al., 2011) and evaluation (Holmes et al., 2011, STECF, 2011a). RBM moves evaluation away from writing detailed prescriptions for activities, but it also brings with it a new set of problems. The environmental impacts have to be clearly defined, and this raises questions such as defining both temporal and spatial definitions of these impacts. From a legal point of view reversing the burden of proof is routed in the precautionary principle. The issue of "who must prove" cannot be treated without looking at the issue of "what must be proved". Secondly, concerning compliance, reversal of the burden of proof comes down to the industry having to foresee the instruments for monitoring and reporting of fishing activities so as to allow for an effective control that the strategies are implemented correctly. Uncertainty in the marine environment is high. In regulatory contexts that uncertainly accumulates over a series of uncertain scientific decisions (Wilson 2009). Under RBM precautionary limits on impacts must be identified with their related indicators, and translated into a burden of proof that has to be met (and paid for) by the industry. While we use the term "industry", it must be kept in mind that a very substantial portion of fishing enterprises in Europe are small businesses taking place in vulnerable rural communities. Hence, there is a strong need to develop methods by which the decrease of uncertainty is cost effective and possible for industry.

\section{Summary and Conclusions}

Stock-based management has the advantage that the units managed and advised upon are broadly agreed upon in e.g. the European fishery system. Even though some stocks are not well defined as actual biological stock units, they are not really questioned as robust advisory and management units today. A fish belongs to a stock and does not change to another stock from time to time. As long as the 
management system keeps focusing on allocation issues for a number of well-defined commercial stocks, stock-based approaches present undeniable advantages in relation to monitoring, control and sharing of resources. However, EBFM requires more comprehensive, integrated, multi-disciplinary and detailed advice for an increasing number of ecosystem elements, even while the available data supporting that advice are limited. It is difficult to see how stock based management alone could provide this.

We believe that a better knowledge of the characteristics and dynamics of the various fishing activities is an obvious and necessary move forward for achieving these new requirements, both for minimising impacts on the ecosystem and ensuring the sustainability of the fisheries exploiting its multiple components. The whole harvesting process cannot be simply reduced to a single fishing mortality estimate that can be tuned in ecosystem-based marine models. Therefore broad conservation objectives can only be reached through a proper understanding and management of the drivers and incentives of the dynamics of the fishery. In this regard, fleet/metier- approaches represent an intermediate layer between the current single-stock level and the level of the individual vessel, which can therefore be used as a convenient and tractable way to define and evaluate management and conservation objectives at the regional level. We have also shown that such fleet-based approaches may not be necessarily best achieved through effort control due to the inherent issues linked to effort definition and quantification, implying that output-based management with a proper control of catches rather than landings (catch quota management, cf. www.fvm.dk/yieldoffish) may indeed be the most suitable path in mixed-fisheries.

Recent history has however clearly shown how difficult it has been to implement such an approach to management within a classical command and control system. Mixed fisheries management is a serious political challenge for managers because questions of fairness among groups of fishers (and between countries) arise more quickly than in any other set of fisheries management problems, and because of the imperfect link between the inputs used for fishing and its outputs in terms of global ecosystem impact. This explains why twenty years of development of management science in this field have not 
fully resolved the key definitions issues that were described here. A bottom line is that the management and monitoring systems requires analytic and bureaucratic definitions of fisheries, but the industry, and sometimes even the environment and marine ecosystems, may pay some real costs when these definitions become overly detailed and restrictive.

There is neither quantitative nor qualitative answer to this issue of definition, and a beneficial way forward is to work towards increased cooperation to establish agreed compromises. At first, it is necessary that the different actors harmonise their views internally. On the scientific and management side, the highest priority should be given to full consistency between the fleet /métier management measures and the scientific data available to monitor and evaluate them. Progress in this direction is encouraging. On the industry side, highest priority should be given to moving away from single-stock management plans and towards integrated regional plans; and to agreeing on the qualitative categories of fleets and métiers they would acknowledge as a relevant basis for management. From that, it might then be possible to link the two, in that the qualitative categories empirically defined by stakeholders may be crossed with the scientific data for quantification and modelling. The continued improvement in the resolution of scientific data may contribute to this at the fine scale. Yet, even when the questions of definitions and categories are resolved, fleet-based approaches to management may still have to be robust and adaptive, rather than precise and prescriptive, because of the changing dynamics of the system.

However, the fundamental issues that the imposition of pre-determined, generic categories poses at the local level, with its evident risk of increased command and control micro-management, suggest that these objectives may be potentially better achieved through results-based management. Here, local actors are left with the flexibility to decide upon the optimal paths towards sustainability. Resultsbased management also allows the complex challenges of an EBFM to be structured hierarchically from the regional stock level using fleet and métier concepts, to the local level of the fishery. This suggests that in the EU, the current efforts towards fleet-based approaches to management should not be decoupled from the other ongoing key issues, such as regionalization or the implementation of 
rights-based management. We also believe that the current EC cod management plan (EC, 2008), while imperfectly designed and implemented so far (STECF, 2011a), is nevertheless a significant and innovative step in this direction, in that it acts at different scales. This plan involves setting broad objectives at the stock level, quantifying the impact of the various fleets and métiers and defining limits to these, as well as encouraging responsible and results-based individual behaviour within fleet segments independent of the activity of others. Improvements and further extensions of this innovative approach are anticipated in the revised CFP (CEC, 2011b).

In conclusion, we underline that although the premises of fleets and métier-based approaches to management were initiated twenty years ago, the main developments have occurred over the most recent years . This has taken place within the scientific community through the DCF and a number of large scale research projects investigating fleet dynamics, as well as the movement towards EBFM and spatial planning. It has also taken place within the management system and with the stakeholders through effort limitation systems. Therefore, experience and lessons are continuously being gained, and the whole system is evolving rapidly towards improved consistency and cooperative management. We hope that a mature stage will be reached in the near future.

\section{Acknowledgements}

This paper summarizes some personal experience and thoughts that the authors have developed among other through participating in a number of EU-funded projects with multi-disciplinary scientific networks of excellence (and in particular EU FP6 EFIMAS and AFRAME), as well as in various ICES and STECF Working Groups, and this continuous financial support is gratefully acknowledged.

Comments and views expressed in this manuscript are those of the authors and do not necessarily represent the views or opinions of their employers or the European Commission. 

manuscript.

\section{References}

572

573

574

575

576

577

578

579

580

581

582

583

584

585

586

587

588

589

590

591

Andersen, B. S., Ulrich, C., Eigaard, O. R., Christensen, A-S. 2012. Short-term choice behaviour in a mixed fishery: investigating métier selection in the Danish gillnet fishery. ICES J. Mar. Sci., 69, 131143.

Andersen, B.S., Vermard, Y., Ulrich, C., Hutton, T., Poos, J.J., 2010. Challenges in integrating shortterm behaviour in a mixed-fishery Management Strategies Evaluation frame: a case study of the North Sea flatfish fishery. Fish. Res., 102, 26-40.

Bannister, R.C.A. 2004. The rise and fall of cod (Gadus morhua, L.) in the North Sea, in: Payne, A.I.L., O’Brien, C.M., Rogers, S.I. (Eds.), Management of Shared Fish Stocks. Blackwell, Oxford, pp. $316-338$.

Bastardie, F., Nielsen, J.R., Andersen, B.S., Eigaard, O.R., 2010a. Effect of fishing effort displacement scenarios on energy efficiency and profitability: an individual-based model applied to Danish fisheries, Fish. Res., 106, 501-516.

Bastardie, F., Nielsen, J.R., Ulrich, C., Egekvist, J., Degel, H., 2010b. Detailed mapping of fishing effort and landings by coupling fishing logbooks with satellite-recorded vessel geo-location. Fish. Res., 106, 41-53. 
601

602

603

604

605

606

607

608

609

610

611

612

613

614

615

616

Bastardie, F., Vinther, M., Nielsen, J.R., Ulrich, C., Storr-Paulsen, M., 2010c. Stock-based vs. fleetbased evaluation of the multi-annual management plan for the cod stocks in the Baltic Sea. Fish. Res., $101,188-202$.

Baudron, A., Ulrich, C., Nielsen, J.R., J. Boje, 2010. Comparative evaluation of a mixed-fisheries effort-management system based on the Faroe Islands example. ICES J. Mar. Sci., 67, 1036-1050.

Beecham, J.A., Engelhard, G.H., 2007. Ideal free distribution or dynamic game? An agent-based simulation study of trawling strategies with varying information. Physica A, 384, 628-646.

Branch, T. A., Hilborn, R., Haynie, A. C., Fay, G., Flynn, L., Griffiths, J., Marshall, K. N., 2006. Fleet dynamics and fishermen behaviour: lessons for fisheries managers. Can. J. Fish. Aquat. Sci., 63, $1647-1668$.

CEC, 2001. Green Paper on the future of the Common Fisheries Policy. COM(2001) 135.

CEC, 2009. Green Paper. Reform of the Common Fishery Policy. COM(2009) 163, 28 pp.

Charles, A. T., Bull, A., Kearney, J., Milley, C., 2005. Community-Based Fisheries in the Canadian Maritimes. in: McClanahan, T., Castilla, J.C. (Eds), Fisheries Management: Progress towards Sustainability. Blackwell, Oxford.

Deporte, N., Ulrich, C., Mahévas, S., Demanèche, S., Bastardie, F., 2012. Regional métier definition: a comparative investigation of statistical methods using a workflow applied to international otter trawl fisheries in the North Sea. ICES J. Mar. Sci., 69, 331-342. 
EC, 2001. Commission Regulation (EC) No 1639/2001 of 25 July 2001 establishing the minimum and

618

621

622

623

624

625

626

627

628

629

630

631

632

633

634

635

636

637

638

639

640

641

642

643

extended Community programmes for the collection of data in the fisheries sector and laying down detailed rules for the application of Council Regulation (EC) No 1543/2000. Official Journal of the European Communities, L 222/53.

EC, 2004. Council Regulation (EC) No 423/2004 of 26 February 2004 establishing measures for the recovery of cod stocks. Official Journal of the European Union, L 70/8.

EC. 2005a. Commission Staff Working Paper: Report of the Ad Hoc Meeting of Independent Experts on Fleet-Fishery based Sampling, Nantes (France), 23-27 May 2005. 34 pp.

EC. 2005b. Council Regulation (EC) No 2166/2005 establishing measures for the recovery of the Southern hake and Norway lobster stocks in the Cantabrian Sea and Western Iberian peninsula and amending Regulation (EC) No 850/98 for the conservation of fishery resources through technical measures for the protection of juveniles of marine organisms. Official Journal of the European Union, L345/5.

EC. 2006. Commission Staff Working Paper: Report of the Ad Hoc Meeting of Independent Experts on Fleet-Fishery based Sampling, Nantes (France), 12-16 June 2006. 98 pp.

EC, 2007. Council Regulation (EC) No 676/2007 of 11 June 2007 establishing a multiannual plan for fisheries exploiting stocks of plaice and sole in the North Sea. Official Journal of the European Union, L $157 / 1$.

EC, 2008a. Commission Decision (2008/949/EC) of 6 November 2008 adopting a multiannual Community programme pursuant to Council Regulation (EC) No 199/2008 establishing a Community framework for the collection, management and use of data in the fisheries sector and support for 
644 scientific advice regarding the common fisheries policy. Official Journal of the European Union, L $645346 / 37$.

646

647 EC, 2008b. Council Regulation (EC) No 1342/2008 of 18 December 2008 establishing a long-term 648 plan for cod stocks and the fisheries exploiting those stocks and repealing Regulation (EC) No 649 423/2004. Official Journal of the European Union, L 348/20.

650

EC, 2011a. Communication from the Commission concerning a consultation on fishing opportunities.

$652 \operatorname{COM}(2011) 298$.

653

654

EC, 2011b. Proposal for a regulation of the European Parliament and of the Council on the Common 655 Fisheries Policy. COM(2011) 425.

656

657

Eigaard, O.R., Thomsen, B., Hovgaard, H., Nielsen, A. Rijnsdorp, A.D., 2011. Fishing power 658 increases from technological development in the Faroe Islands longline fishery. Can. J. Fish. Aquat. 659 Sci., 68, 1970-1982.

660

661

Eigaard, O.R., Munch-Petersen, S., 2010. Influence of fleet renewal and trawl development on 662 landings per unit effort of the Danish northern shrimp (Pandalus borealis) fishery. ICES J. Mar. Sci., $68,26-31$.

664

Eigaard, O.R., 2009. A bottom up approach to technological development and its management 666 implications in a commercial fishery. ICES J. Mar. Sci., 66, 916-927.

667

668

Fitzpatrick, M., Graham, N., Rihan, D.J., Reid, D.G., 2011. The burden of proof in co-management 669 and results-based management: the elephant on the deck! ICES J. Mar. Sci., 68, 1656-1662. 
671 Fulton, E.A., Smith, A.D.M., Smith, D.C. van Putten, I.E., 2011. Uncertainty in fisheries management. 672 Fish Fish., 12, 2-17.

673

674 Gallie, W.B. 1955. Essentially Contested Concepts. Proceedings of the Aristotelian Society, 56,16767598.

676

677 Gascuel, D., Merino, G., Döring, R., Druon, J.N., Goti, L., Guénette, S., Macher, C., Soma, K., 678 Travers-Trolet, M., Mackinson, S., 2012. Towards the implementation of an integrated ecosystem 679 fleet-based management of European fisheries. Mar. Pol., 36, 1022-1032.

680

681

Hamon, K., Ulrich, C., Hoff, A., Kell, L.T., 2007. Evaluation of management strategies for the mixed

682

North Sea roundfish fisheries with the FLR framework, in: Oxley, L., Kulasiri, D. (Eds), MODSIM

683

2007 International Congress on Modelling and Simulation. Modelling and Simulation Society of

684 Australia and New Zealand, December 2007, 2813-2819.

685

Hilborn, R., 2007. Managing fisheries is managing people: what has been learned? Fish Fish., 8, 285-

687 296.

688

689

Hintzen, N.T., Bastardie, F., Beare, D.J.B., Piet, G., Ulrich, C., Deporte, N., Egekvist, J., Degel, H., 690 2012. vmstools: open-source software for the processing, analysis and visualization of fisheries logbook and VMS data. Fish. Res.,115-116, 31-43.

692

693

Holland, D.S., 2007. Managing Environmental Impacts of Fishing: Input Controls versus Outcome 694 Oriented Approaches. Int. J. Global Environ. Issues, 7, 255-272

695 
696

697

698

699

700

701

702

703

704

705

706

707

708

709

710

711

712

713

714

715

716

717

718

719

720

721

Holmes, S.J., Bailey, N., Campbell, N., Catarino, R., Barratt, K., Gibb, A., Fernandes, P.G., 2011.

Using fishery-dependent data to inform the development and operation of a co-management initiative to reduce cod mortality and cut discards. ICES J. Mar. Sci., 68, 1679-1688.

ICES, 2003. Report of the Study Group on the development of fishery-based forecasts. CM 2003/ACFM: 08.

ICES, 2010. Report of the Joint ICES - STECF Workshop on methods for merging metiers for fishery based sampling (WKMERGE), 19-22 January 2010, Copenhagen, Denmark. ICES CM 2010/ACOM:40 . 94 pp.

ICES, 2011a. Report of the Working Group on the Assessment of Demersal Stocks in the North Sea and Skagerrak (WGNSSK), 4 - 10 May 2011, ICES Headquarters, Copenhagen. ICES CM 2011/ACOM:13. 1190 pp.

ICES, 2011b. Report of the Working Group on Mixed Fisheries Advice for the North Sea (WGMIXFISH), 29 August - 2 September 2011, ICES Headquarters, Copenhagen, Denmark. ICES CM 2011/ACOM:22. 94 pp.

Jacobsen, R.B., Damalas, D., Delaney, A., Wilson, D.C., 2009. Stakeholder perceptions of groups of boats. Interview and pile sorts from 12 ports in Scotland, England, Holland, Denmark, France, Basque Country and Greece. Deliverables 6.1 and 6.2 for A framework for fleet and area based fisheries management (AFRAME) Project. EU Sixth Framework Programme Contract no.: 044168

Jákupsstovu, S.H.í, Cruz, L. R., Maguire, J-J., Reinert, J., 2007. Effort regulation of the demersal fisheries at the Faroe Islands: a 10-year appraisal. ICES J. Mar. Sci., 64, 730-737 
723 Kell, L.T., Mosqueira, I., Grosjean, P., Fromentin, J-M., Garcia, D., Hillary, R., Jardim, E., Mardle, S., 724 Pastoors, M.A., Poos, J.J., Scott, F., Scott, R.D., 2007. FLR: an open-source framework for the evaluation and development of management strategies. ICES J. Mar. Sci., 64, 640-646.

726

Kindt-Larsen, L., Kirkegaard, E., Dalskov, J., 2011. Fully documented fishery: a tool to support a catch quota management system. ICES J. Mar. Sci., 68, 1606-1610.

Kraak, S.B.M., Buisman, E.C., Dickey-Collas, M., Poos, J.J., Pastoors, M.A., Smit, J.G.P., van

Oostenbrugge, J.A.E., Daan, N., 2008. The effect of management choices on the sustainability and economic performance of a mixed fishery: a simulation study. ICES J. Mar. Sci., 65, 697-712.

Laurec, A., Biseau, A., Charuau, A., 1991. Modelling technical interactions. ICES Mar. Sci. Symp., $193,225-236$.

Loucks, L. 1998. Sambro Community Quota Fisheries Management: A Case of Innovative Fisheries, Managing Ourselves. Halifax, Gorsebrook Research Institute for Atlantic Canada Studies, 54-58.

Mahévas, S., Vermard, Y., Hutton, T., Iriondo, A., Jadaud, A., Maravelias, C. D., Punzón, A., Sacchi, human vs. technology-induced variation in catchability for a selection of European fishing fleets. ICES J. Mar. Sci., 68, 2252-2263.

Marchal, P., 2008. A comparative analysis of métiers and catch profiles for some French demersal and pelagic fleets. ICES J. Mar. Sci., 65, 674-686. 
750 Marchal, P., Andersen, B., Bromley, D., Iriondo, A., Mahévas, S., Quirijns, F., Rackham, B.,

751 Santurtun, M., Tien, N., Ulrich, C., 2006. Improving the definition of fishing effort for important

752 European fleets by accounting for the skipper effect. Can. J. Fish. Aquat. Sci., 63, 510-533.

753

754

Marchal, P., Andersen. B., Caillart, B., Eigaard, O., Guyader, O., Hovgaard, H., Iriondo, A., Le Fur,

F., Sacchi, J., Santurtún, M. 2007. Impact of technological creep on fishing effort and fishing mortality, for a selection of European fleets. ICES J. Mar. Sci.,, 64, 192-209.

757

Marchal, P., Nielsen, J.R., Hovgård, H., and Lassen, H. 2001. Time changes in fishing power in

Danish cod fisheries of the Baltic Sea. ICES J. Mar. Sci., 58, 298-310.

760

761

Motos, L., Wilson, D.C., (Eds), 2006. The Knowledge Base for Fisheries Management. Developments in Aquaculture and Fisheries Science Series, Volume 36. Elsevier.

763

Needle, C. L., and Catarino, R. 2011. Evaluating the effect of real-time closures on cod targeting.

ICES J. Mar. Sci., 68, 1647-1655.

766

Nielsen, J.R., Limborg, M., 2009. Managing fleets and fisheries rather than single stocks - conceptual change in European fisheries management advice. World Fish. 58, 8-9.

769

Nielsen, J.R.*, Sparre, P.J.*, Hovgaard, H.*, Frost, H.*, Tserpes, G.*, 2006. Effort and Capacity 
Pascoe, S., Punt, A. E. Dichmont, C. M., 2010. Targeting ability and output controls in Australia's multi-species Northern Prawn Fishery. Eur. Rev. Agr. Econ., 37, 313-334.

Pascoe, S., Robinson, C., 1998. Input controls, input substitution and profit maximisation in the English Channel beam trawl fishery. J. Agr. Econ., 49, 16-33.

Pelletier, D., Ferraris, J., 2000. A multivariate approach for defining fishing tactics from commercial catch and effort data. Can. J. Fish. Aquat. Sci., 57, 51-65.

Pelletier, D., Mahévas, S., Drouineau, H., Vermard, Y., Thebaud, O., Guyader, O., Poussin, B., 2009. Evaluation of the bioeconomic sustainability of multi-species multi-fleet fisheries under a wide range of policy options using ISIS-Fish. Ecol. Model., 220, 1013-1033.

Poos, J.J., Bogaards, J.A., Quirijns, F.J., Gillis, D.M., Rijnsdorp, A.D., 2010. Individual quotas, fishing effort allocation, and over-quota discarding in mixed fisheries. ICES J. Mar. Sci., 67, 323-333.

Prellezo. R., Accadia, P., Andersen, J.L., Andersen, B.S., Buisman E., Little, A, Nielsen, J.R., Poos, J.J., Powell, J., Röckmann, C., 2012. A review of EU bio-economic models for fisheries: The value of a diversity of models. Mar. Pol., 36, 423-431.

Reeves, S.A., Marchal, P, Mardle, S., Pascoe, S., Prellezo, R., Thébaud, O., Travers, M., 2008. From fish to fisheries: the changing focus of management advice, in: Payne, A., Cotter, J., Potter, T., (Eds), Advances in Fisheries Science. 50 years on from Beverton and Holt. Blackwell Publishing. 135-154.

Rosenberg, A.A., Restrepo, V.R., 1994. Uncertainty and risk evaluation in stock assessment advice for U. S. marine fisheries. Can. J. Fish. Aquat. Sci., 51, 2715-2720. 
802

803

804

805

806

807

808

809

810

811

812

813

814

815

816

817

818

819

820

821

822

823

824

825

826

827

Squires, H., Renn, O. 2011. Can Participatory Modelling Support Social Learning in Marine

Fisheries? Reflections from the Invest in Fish South West Project. Environ. Policy Govern., 21: 403416.

STECF, 2010a. Report of the SGMOS-10-05 Working Group on Fishing Effort Regimes Regarding Annexes IIA, IIB and IIC of TAC \& Quota Regulations, Celtic Sea and Bay of Biscay. Bailey, N., Rätz, H.-J. (Eds). Publications Office of the European Union, Luxembourg, EUR 24809 EN JRC64928, 323 pp.

STECF, 2010b. The 2010 Annual Economic Report on the European Fishing Fleet. Anderson, J., Guillen, J. (Eds). Publications Office of the European Union, Luxembourg, EUR 24554 EN JRC $59885,688 \mathrm{pp}$

STECF, 2011a. Evaluation of multi-annual plans for cod in Irish Sea, Kattegat, North Sea, and West of Scotland (STECF-11-07). Simmonds, J., Kraak, S. (Eds). Publications Office of the European Union, Luxembourg, EUR 24901 EN JRC 66051, 358 pp.

STECF, 2011b. Reflections on the Present and Future Requirements of the DCF (STECF-11-04). Connolly, P., Virtanen, J., (Eds). Publications Office of the European Union, Luxembourg, EUR 24896 EN, JRC 66003, 161 pp.

Tserpes, G.*, Peristeraki, P.*, Nielsen, J.R.*, 2006. Ecological Side-Effects of Fishing from the Fisheries Management Perspective, in: Motos, L., Wilson, D.C. (Eds), The Knowledge Base for Fisheries Management. Developments in Aquaculture and Fisheries Sciences Series, 36. Elsevier. pp. 267-294. *Authorship equal. 
Ulrich, C., Andersen, B.S., 2004. Dynamics of fisheries, and the flexibility of vessel activity in Denmark between 1989 and 2001. ICES J. Mar. Sci., 61, 308-322.

Ulrich, C., Reeves, S.A., Vermard, Y., Holmes, S.J., Vanhee, W., 2011. Reconciling single-species TACs in the North Sea demersal fisheries using the Fcube mixed-fisheries advice framework. ICES J. Mar. Sci., 68, 1535-1547.

Ulrich, C., Reeves, S.A., Kraak, S.B.M., 2008. Mixed Fisheries and the Ecosystem Approach. ICES Insight, 45, 36-39.

Ulrich, C., Wilson, D.C., 2009. Rights-Based Management and Participatory Governance in South West Nova Scotia. in: Hauge, K.H., Wilson, D.C. (Eds.) Comparative Evaluations of Innovative Fisheries Management: Global Experiences and European Prospects. Dordrecht, The Netherlands: Springer Publishing, 43-68.

Van Oostenbrugge, H.J.A.E., Powell J.P., Smit J.P.G., Poos J.J., Kraak S.B.M., Buisman E.F.C., 2008. Linking catchability and fisher behaviour under effort management. Aquat. Living Resour., 21, 265273.

Vinther, M., Reeves, S.A., Patterson, K.R., 2004. From single-species advice to mixed-species management: taking the next step. ICES J. Mar. Sci., 61, 1398-1409.

Wilson D.C., 2009. The paradoxes of transparency. Science and the ecosystem approach to fisheries management in Europe. Amsterdam: Amsterdam University Press. 
853 Wilson, D.C., Jacobsen, R.B., 2009. Governance Issues in Mixed-Fisheries Management: An Analysis 854 of Stakeholder Views. Deliverable 6.3 for A framework for fleet and area based fisheries management 855 (AFRAME) Project . EU Sixth Framework Programme Contract no.: 044168.

856

857 Witherell, D., Pautzke, C., Fluharty, D., 2000. An ecosystem-based approach for Alaska groundfish 858 fisheries. ICES J. Mar. Sci.,, 57, 771-777.

859

860 Wolff, F., Hauge, K.H., 2009. Abundant fish stocks and profitable fisheries off Alaska - a study on 861 harvest control rules and pollock cooperatives. in: Hauge, K.H., Wilson, D.C. (Eds) Comparative 862 Evaluations of Innovative Fisheries Management: Global Experiences and European Prospects.

863 Dordrecht, The Netherlands: Springer Publishing. 


\section{Figures Caption}

866 Figure 1. Conceptual diagram of the links between fleets, métiers and species in a mixed-fishery

867 context.

868 Figure 2. Conceptual view on scales for modeling the fishing mortality $F$ on an hypothetical stock in a

869 given management area (a) Stock-based $F$ applying an overall stock-specific $F$ on the stock; (b) Fleet-

870 or metier-based $\mathrm{F}$ after pooling vessels and/or activities with similar exploitation patterns; (c) Spatially

871 and seasonally explicit fleet-based $F$ and (d) Individual vessel-based $F$ describing the catch removal

872 over the area vessel by vessel. Situations a and b are irrespective of the stock distribution while

873 situations $\mathrm{c}$ and $\mathrm{d}$ are applied on an hypothetical underlying stock abundance distribution (grey levels).

874

875

876 
877 Table 1. Overview over the number of regulated gear categories (top value) and corresponding

878 special conditions (bottom value) by year in the EU Cod Management plan for the North Sea,

879 Skagerrak and Eastern English Channel. (From ICES, 2009)

880

\begin{tabular}{|l|c|c|c|c|c|c|c|}
\hline Gear type & 2003 & 2004 & 2005 & 2006 & 2007 & 2008 & 2009 \\
\hline Pemersal Trawls, seines, towed gears & 3 & 3 & 3 & 5 & 5 & 5 & 3 \\
& - & 2 & 4 & 15 & 17 & 17 & - \\
\hline Beam trawl & 1 & 1 & 1 & 4 & 4 & 4 & 2 \\
\hline Static demersal nets & - & - & 1 & 5 & 5 & 5 & - \\
\hline Gillnets & 1 & 1 & 1 & - & - & - & - \\
& - & 2 & 2 & - & - & - & - \\
\hline Trammel & - & - & - & 2 & 4 & 4 & 1 \\
\hline Total & - & - & - & 1 & 1 & 1 & - \\
\hline & - & - & - & 1 & 1 & 1 & 1 \\
\hline
\end{tabular}

881 
883 Figure 1.

Fleet (vessel) Métier (trip) Species (catches)

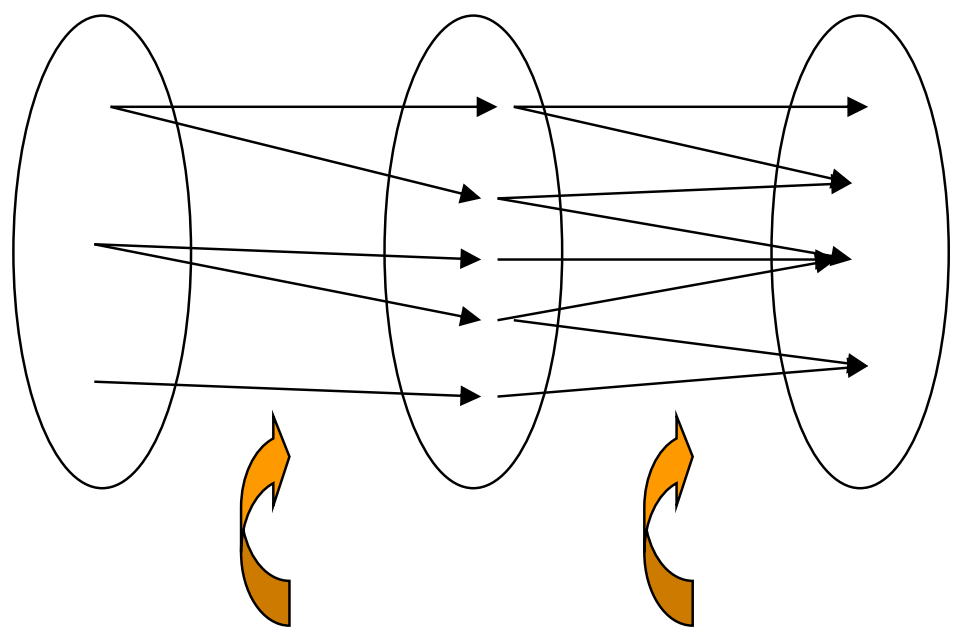

EFFORT CATCHABILITY

884 
Figure 2

(a)

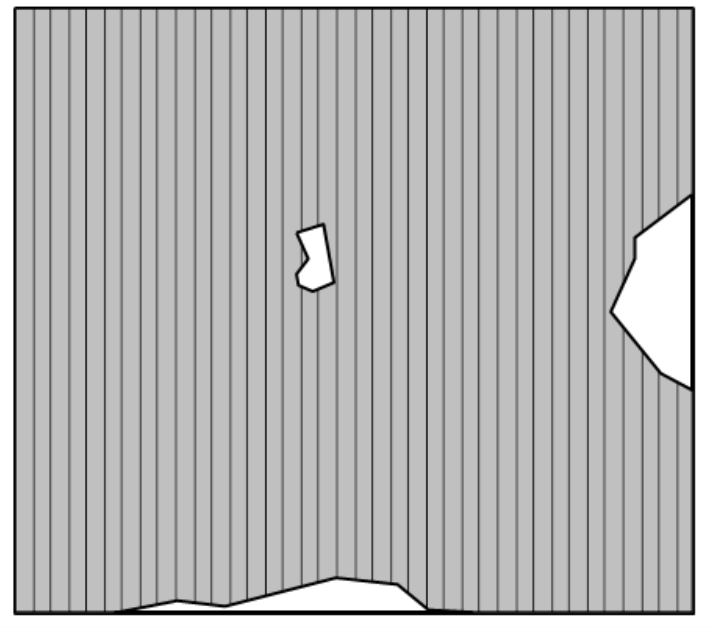

(c)

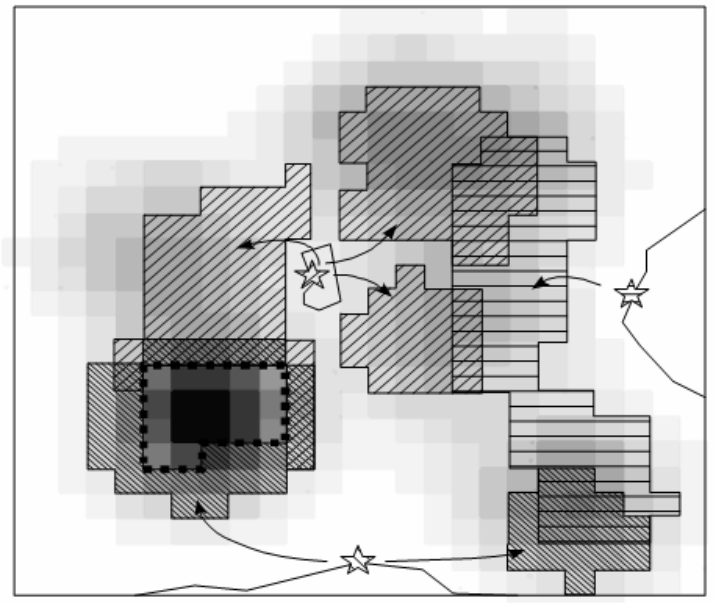

(b)

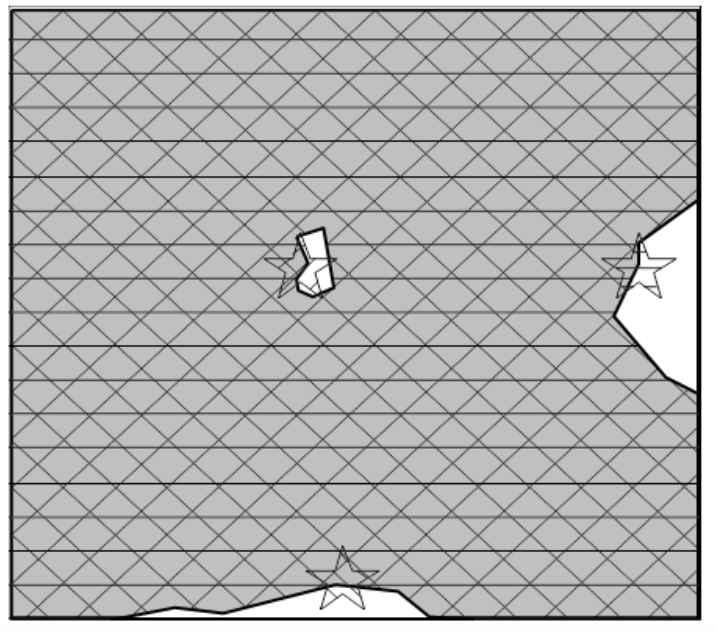

(d)

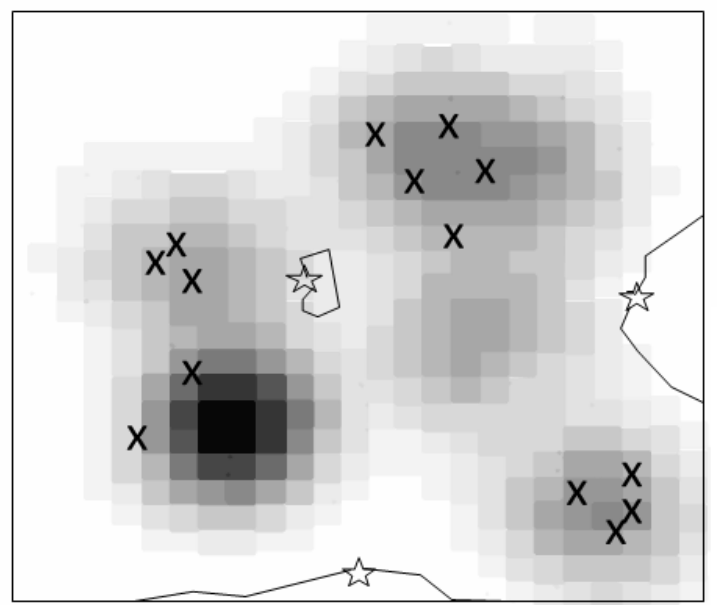

